\title{
Predicting Ventricular Arrhythmias and In-Hospital Mortality in Acute Coronary Syndrome Patients Presenting to the Emergency Department
}

\author{
Azlan Helmy Abd Samat ${ }^{1, \star}$, Hashim Embong ${ }^{1}$, \\ Husyairi Harunarashid ${ }^{1}$, Oteh Maskon ${ }^{2}$
}

\author{
${ }^{1}$ Department of Emergency Medicine, \\ Faculty of Medicine, Universiti \\ Kebangsaan Malaysia Medical Centre, \\ Jalan Yaacob Latif, 56000 Cheras, Kuala \\ Lumpur, Malaysia \\ ${ }^{2}$ Cardiology Unit, Department of \\ Medicine, Faculty of Medicine, Universiti \\ Kebangsaan Malaysia Medical Centre, \\ Jalan Yaacob Latif, 56000 Cheras, Kuala \\ Lumpur, Malaysia

\section{*Correspondence} \\ azlanhelmy@ukm.edu.my \\ (Azlan Helmy Abd Samat)
}

\begin{abstract}
Background: Ventricular arrhythmias (VA) after acute coronary syndrome (ACS) is associated with a higher risk of mortality. This study sought to examine the incidence, predictors and outcome of VA in ACS patients. Material and methods: A prospective cross-sectional study was conducted at the emergency department (ED), Universiti Kebangsaan Malaysia Medical Centre (UKMMC) in Kuala Lumpur, Malaysia. Patients with acute coronary syndrome (ST-segment elevation myocardial infarction [STEMI] and non-ST-segment elevation acute coronary syndrome [NSTEACS]) were continuously monitored for the occurrence of VA. Results: A total of 144 patients were recruited (67 STEMI and 77 NSTE-ACS). The total rate of VA was $18.8 \%(n=27)$ and $14.6 \%(\mathrm{n}=21)$ experienced malignant ventricular arrhythmias (MVA) (8 ventricular fibrillation, 11 sustained ventricular tachycardia and 2 torsades de pointes). In-hospital mortality was reported in $11.1 \%$ of the subjects ( $\mathrm{n}=$ 16). Factors predicted the occurrence of VA was Killip class IV (OR 8.67, 95\% confidence interval [CI] 2.08-36.70, $\mathrm{p}<0.05)$. Meanwhile, occurrence of MVA (OR 86.37, 95\% CI 4.16 - 1792.70, p < 0.05) and blood sugar level (OR 1.30, 95\% CI $1.01-1.67, \mathrm{p}<0.05$ ) independently predicted in-hospital mortality. Conclusion: Incidence of VA was higher than the global estimate and the development of malignant forms of VA during hospitalization for ACS was associated with higher in-hospital mortalities.
\end{abstract}

\section{Keywords}

Acute coronary syndrome, Risk factor, Arrhythmias, Emergency, Mortality

\section{Introduction}

Ventricular arrhythmia (VA) increases the risk of death by sixfold, and it is a well-recognized complication following an acute myocardial infarction [1]. Ventricular fibrillation (VF), ventricular tachycardia (VT), and torsade de pointes (TdP) are forms of cardiac VAs, and their occurrence can be life-threatening [2]. The possible mechanisms for VA occurrence are associated with multiple factors, which include cardiac cell ischemia, scarring, electrolyte disturbances, medications, and advancing age [3-6].

VA is independently associated with an increased risk of in-hospital mortality among patients with acute ST seg- ment elevation myocardial infarction (STEMI) [7], while, in the non-ST-segment elevation acute coronary syndrome (NSTE-ACS), the occurrence is much less, with the incidence being $10 \%$ and $2.6 \%$, respectively, [8, 9]. Early detection of high-risk patients will guide clinicians in the emergency department (ED) to institute early corrective measures to prevent VA occurrence and to guide appropriate ward disposition [10]. Furthermore, VA is more likely to occur during the first $12-48$ hours of ACS onset [10], highlighting the significance of early detection and preventive measures.

Despite being an established malignant complication for ACS, limited data are available regarding the incidence, 
T A B L E 1. Demographic and clinical characteristics of the subjects $(n=144)$.

\begin{tabular}{|c|c|}
\hline Characteristics & Results \\
\hline \multicolumn{2}{|l|}{ Demographic } \\
\hline Mean age \pm SD (hours) & $58.8 \pm 12.8$ \\
\hline \multicolumn{2}{|l|}{ Gender, $\mathrm{n}(\%)$ : } \\
\hline Male & $124(86.1)$ \\
\hline Female & $20(13.9)$ \\
\hline \multicolumn{2}{|l|}{ Race, n (\%): } \\
\hline Malay & $71(49.3)$ \\
\hline Chinese & $49(34.0)$ \\
\hline Indian & $14(9.7)$ \\
\hline Others & $10(6.9)$ \\
\hline \multicolumn{2}{|l|}{ Clinical } \\
\hline \multicolumn{2}{|l|}{ Vital signs on ED arrival: } \\
\hline Mean SBP \pm SD $(\mathrm{mmHg})$ & $134.5 \pm 32.9$ \\
\hline Mean $\mathrm{DBP} \pm \mathrm{SD}(\mathrm{mmHg})$ & $76.7 \pm 18.0$ \\
\hline Mean heart rate $\pm \mathrm{SD}$ (beats/minute) & $82.3 \pm 23.2$ \\
\hline \multicolumn{2}{|l|}{ Diagnosis, $\mathrm{n}(\%)$ : } \\
\hline STEMI & $67(46.5)$ \\
\hline NSTE-ACS & $77(53.5)$ \\
\hline Median time from symptom onset to ED arrival (IQR) (hours) & $3.0(8.0)$ \\
\hline \multicolumn{2}{|l|}{ Present of comorbidities, $\mathrm{n}(\%)$ : } \\
\hline Diabetes mellitus & $73(50.7)$ \\
\hline Hypertension & $100(69.4)$ \\
\hline Kidney disease & $26(18.1)$ \\
\hline Hypercholesterolemia & $56(38.9)$ \\
\hline Smoking & $53(36.8)$ \\
\hline Chronic obstructive pulmonary disease & $5(3.5)$ \\
\hline Previous PCI & $18(12.5)$ \\
\hline Previous CABG & $13(9.0)$ \\
\hline \multicolumn{2}{|l|}{ Laboratory: } \\
\hline Mean blood sugar $\pm \mathrm{SD}(\mathrm{mmol} / \mathrm{L})$ & $11.6 \pm 6.4$ \\
\hline Mean leucocytes \pm SD (X 109/L) & $11.7 \pm 4.5$ \\
\hline Mean hemoglobin $\pm \mathrm{SD}(\mathrm{g} / \mathrm{dl})$ & $13.5 \pm 2.0$ \\
\hline Mean potassium $\pm \mathrm{SD}(\mathrm{mmol} / \mathrm{L})$ & $4.0 \pm 0.4$ \\
\hline \multicolumn{2}{|l|}{ Electrocardiographic features: } \\
\hline ST-segment depression, $\mathrm{n}(\%)$ & $92(63.9)$ \\
\hline ST-segment elevation, $\mathrm{n}(\%)$ & $76(52.8)$ \\
\hline T-wave inversion, $\mathrm{n}(\%)$ & $52(36.1)$ \\
\hline Mean heart rate $\pm \mathrm{SD}(\mathrm{msec})$ & $83 \pm 25$ \\
\hline Mean PR interval \pm SD $(\mathrm{msec})$ & $172 \pm 38$ \\
\hline Mean QT interval \pm SD (msec) & $424 \pm 40$ \\
\hline \multicolumn{2}{|l|}{ Killip classification, $\mathrm{n}(\%)$ : } \\
\hline I & $60(41.7)$ \\
\hline II & $16(11.1)$ \\
\hline III & $7(4.9)$ \\
\hline IV & $18(12.5)$ \\
\hline \multicolumn{2}{|l|}{ Treatment options, n (\%): } \\
\hline STEMI patients received thrombolysis & $42(29.2)$ \\
\hline STEMI patients with failed thrombolysis & 0 \\
\hline Number of patients who had angiogram/PCI (including PPCI) & $47(32.6)$ \\
\hline
\end{tabular}


peak time of occurrence, and factors associated with VA in Malaysia. The objectives of this study were to describe the time-based incidence, risk factors, and clinical outcome associated with VA among patients admitted with ACS.

\section{Methods}

\subsection{Study design and setting}

This was a prospective single-center study conducted over a period of one year from May 1st, 2014, until May 31st, 2015. The study took place at the ED of Universiti Kebangsaan Malaysia Medical Center (UKMMC), an urban tertiary teaching hospital, in Kuala Lumpur, serving 72,000 patients annually. A cardiology consultation unit was available under the department of internal medicine, which offered cardiac catheterization procedure during working hours (8 am to $5 \mathrm{pm}$ ).

\subsection{Subjects}

The study recruited adult patients, aged 18 years and above, who presented to the ED with a presumptive diagnosis of ACS. The diagnosis was established based on the typical clinical history of ACS, such as angina pain at rest, and the patients were diagnosed as having either STEMI or NSTE-ACS based on the electrocardiographic changes [1113]. Selection of patients with STEMI was according to the electrocardiographic presence of new ST elevation at the $\mathrm{J}$ point in at least two contiguous leads $\geq 2 \mathrm{~mm}$ in men or $\geq 1.5 \mathrm{~mm}$ in women in leads V2-V3 and/or of $\geq 1 \mathrm{~mm}$ in other contiguous chest or limb leads or presumed new left bundle branch block at the time of ED admission with likely ischemic chest pain, with or without raised cardiac biomarkers [12, 14]. Meanwhile, the selection of patients with NSTE-ACS, which encompassed non-ST-elevation myocardial infarction (NSTEMI) and unstable angina (UA), was made based on the absence of ST elevation on the electrocardiogram (ECG) in patients with likely ischemic chest pain, with or without raised cardiac biomarkers. The study excluded patients known to have VA due to conditions such as Brugada syndrome and Wolff-Parkinson-White syndrome. Patients who were brought in dead to the ED and ACS patients who were diagnosed in other centers and transferred to the ED for further treatments were also excluded.

\subsection{Study protocol}

During the course of the study, patients were treated according to the institutional protocol [15]. All patients received dual antiplatelet therapy with aspirin and clopidogrel in the ED. Patients with STEMI received reperfusion therapy by either primary percutaneous coronary intervention (PPCI) or fibrinolysis. Meanwhile, patients with NSTEACS received low-molecular-weight heparins. All patients provided written informed consent. The study received approval from UKMMC research ethics committee (study code: FF-2014-278).
All data were collected using a standardized data collection sheet. Demographic and clinical characteristics were obtained, including comorbidities, smoking history, duration of symptoms, vital signs at presentation, biochemical parameters, electrocardiographic features, and treatment outcome. All cases were categorized into either one of the following diagnosis of ACS: STEMI or NSTE-ACS.

The study determined two main outcomes: the incident of VA and in-hospital mortality. Patients were monitored for occurrence of VA within 72 hours of hospitalization. All types of VA defined as VF, sustained and nonsustained VT, torsade des pointes (TdP) polymorphic VT, and episodes of trigeminy, bigeminy, or couplet premature ventricular complexes (PVCs) [2] were recorded.

Concomitant VT and VF were categorized as VF. The three forms of VA associated with poor clinical outcome, VF, sustained VT, and TdP, were categorized as malignant ventricular arrhythmias (MVAs) [16], whilst nonsustained VT and episodes of PVCs were not considered MVAs. All deaths that occurred during hospitalization (in-hospital mortality) were recorded.

VF was defined as irregular ECG waves of inconsistent shape and unidentifiable QRS complexes accompanied by hemodynamic compromise requiring immediate defibrillation.

Sustained VT was defined as a series of consecutive regular broad complex ectopic ventricular beats, at a rate of $>100$ beats $/ \mathrm{min}$, lasting $>30$ seconds, which selfterminated or required pharmacological cardioversion or was accompanied by a hemodynamic instability requiring electrical cardioversion. Nonsustained VT was defined as $\geq 3$ consecutive broad complex ventricular ectopic beats, at a rate of $>100$ beats $/ \mathrm{min}$, lasting $<30$ seconds, and not accompanied by a hemodynamic compromise. Polymorphic VT TdP was defined as a broad complex QRS of a variable morphology with characteristic twisted points in the setting of a prolonged QT interval.

\subsection{Sample size and statistical analysis}

Categorical and continuous data were presented as percentages and mean or median, respectively. Baseline characteristics of subjects between groups were compared using chi-square for categorical variables and Student's t-test or Mann-Whitney U test for continuous variables. To identify the statistically significant predictors to VA and in-hospital mortality, statistically significant $(\mathrm{p}<0.1)$ variables from univariate analysis were subjected to multivariate logistic regression analysis. The results were presented as odds ratio (OR) with $95 \%$ confidence interval $(\mathrm{CI})$, and a $\mathrm{p}$ value $<0.05$ was considered significant. The Statistical Package for Social Sciences (SPSS Inc., Chicago, IL, USA, Version 22.0) was used for the statistical analysis.

\section{Results}

A total of 145 patients were consented for enrollment. The diagnosis of one subject was later revised to be myocarditis, 
TA B L E 2. Baseline characteristics by VA.

\begin{tabular}{|c|c|c|c|}
\hline \multirow[t]{2}{*}{ Variables } & \multicolumn{2}{|c|}{ Occurrence of VA } & \multirow[b]{2}{*}{ p value } \\
\hline & Yes & No & \\
\hline & $n=27(18.8 \%)$ & $n=117(81.2 \%)$ & \\
\hline Mean age \pm SD, years & $56.4 \pm 14.1$ & $59.3 \pm 12.4$ & 0.284 \\
\hline \multicolumn{4}{|l|}{ Gender, n (\%): } \\
\hline Male & $22(81.5)$ & $102(87.2)$ & \\
\hline Female & $5(18.5)$ & $15(12.8)$ & 0.536 \\
\hline \multicolumn{4}{|l|}{ Race, n (\%): } \\
\hline Malay & $17(63.0)$ & $54(46.2)$ & \\
\hline Chinese & $9(33.3)$ & $40(34.2)$ & \\
\hline Indian & $1(9.7)$ & $13(11.1)$ & \\
\hline Others & 0 & $10(8.5)$ & 0.186 \\
\hline \multicolumn{4}{|l|}{ Diagnosis, n (\%): } \\
\hline STEMI & $18(66.7)$ & $49(41.9)$ & \\
\hline NSTE-ACS & $9(33.3)$ & $68(58.1)$ & 0.031 \\
\hline Median time from symptom onset to ED arrival (IQR) (hours) & $2.0(4.0)$ & $4.0(10.0)$ & 0.036 \\
\hline \multicolumn{4}{|l|}{ Mean blood pressure $\pm \mathrm{SD}, \mathrm{mmHg}$ : } \\
\hline Systolic blood pressure & $121.5 \pm 33.0$ & $136.7 \pm 31.9$ & 0.032 \\
\hline Diastolic blood pressure & $71.9 \pm 21.6$ & $77.3 \pm 17.4$ & 0.179 \\
\hline Mean heart rate $\pm \mathrm{SD}$, beats $/ \mathrm{min}$ & $84.5 \pm 27.0$ & $80.6 \pm 21.4$ & 0.429 \\
\hline \multicolumn{4}{|l|}{ Baseline blood laboratory data: } \\
\hline Blood sugar, mean $\pm \mathrm{SD}, \mathrm{mmol} / \mathrm{L}$ & $11.4 \pm 6.9$ & $11.4 \pm 6.2$ & 0.996 \\
\hline Leucocytes, mean \pm SD, x109/L & $13.3 \pm 6.5$ & $11.4 \pm 4.1$ & 0.057 \\
\hline Potassium, mean $\pm \mathrm{SD}, \mathrm{mmol} / \mathrm{L}$ & $4.0 \pm 0.4$ & $4.1 \pm 0.5$ & 0.81 \\
\hline Hemoglobin, mean $\pm \mathrm{SD}, \mathrm{g} / \mathrm{dL}$ & $13.2 \pm 2.6$ & $13.5 \pm 1.8$ & 0.514 \\
\hline \multicolumn{4}{|l|}{ Comorbidities, n (\%): } \\
\hline HTN & $19(69.9)$ & $81(69.8)$ & 1 \\
\hline COPD & $1(3.7)$ & $4(3.6)$ & 1 \\
\hline $\mathrm{DM}$ & $11(40.7)$ & $62(54.4)$ & 0.282 \\
\hline Kidney disease & $6(22.2)$ & $20(17.5)$ & 0.586 \\
\hline Hypercholesterolemia & $8(29.6)$ & $48(41.7)$ & 0.281 \\
\hline Smoking history & $10(37.0)$ & $43(38.4)$ & 1 \\
\hline History of PCI & $5(18.5)$ & $13(11.6)$ & 0.345 \\
\hline History of CABG & $3(11.1)$ & $10(8.8)$ & 0.716 \\
\hline \multicolumn{4}{|l|}{ Electrocardiographic features: } \\
\hline ST-segment depression, n (\%) & $22(81.5)$ & $70(59.8)$ & 0.071 \\
\hline ST-segment elevation, n (\%) & $18(66.7)$ & $58(49.6)$ & 0.198 \\
\hline T-wave inversion, $\mathrm{n}(\%)$ & $8(29.6)$ & $44(37.6)$ & 0.507 \\
\hline Mean heart rate \pm SD (msec) & $87 \pm 29$ & $81 \pm 23$ & 0.266 \\
\hline Mean PR interval \pm SD $(\mathrm{msec})$ & $167 \pm 50$ & $173 \pm 34$ & 0.42 \\
\hline Mean QT interval \pm SD $(\mathrm{msec})$ & $434 \pm 58$ & $421 \pm 33$ & 0.144 \\
\hline \multicolumn{4}{|l|}{ Killip classification, n (\%): } \\
\hline I & $8(30.8)$ & $52(69.3)$ & \\
\hline II & $4(15.4)$ & $12(16.0)$ & \\
\hline III & $3(11.5)$ & $4(5.3)$ & \\
\hline IV & $11(42.3)$ & $7(9.3)$ & 0.001 \\
\hline \multicolumn{4}{|l|}{ Treatment, n (\%): } \\
\hline Thrombolysis & $12(44.4)$ & $30(25.6)$ & 0.063 \\
\hline $\mathrm{PCI} /$ angiogram & $6(22.2)$ & $41(35.0)$ & 0.177 \\
\hline
\end{tabular}


TA B L E 3. Multivariate logistic analysis of predictors to VA.

\begin{tabular}{lccc} 
Variable & OR & $\mathbf{9 5 \%}$ CI & p value \\
Diagnosis of ACS (STEMI vs. NSTE-ACS) & 1.16 & $0.35-3.81$ & 0.808 \\
Duration of onset (hours) & 0.97 & $0.93-1.01$ & 0.161 \\
Baseline systolic blood pressure, mmHg & 0.99 & $0.98-1.01$ & 0.597 \\
Leucocyte count, X 10 9 L & 1 & $0.90-1.12$ & 0.914 \\
Killip class (reference: class I) & & & \\
Killip class II & 2.78 & $0.64-12.10$ & 0.172 \\
Killip class III & 3.88 & $0.67-22.64$ & 0.132 \\
Killip class IV & 8.67 & $2.08-36.70$ & $\mathbf{0 . 0 0 3}$ \\
\hline
\end{tabular}

and the patient was excluded from the study. The final analysis included 144 subjects. The mean age of all subjects was 58.7, ranging from 31 to 90 years. The majority of the subjects were males, $124(86 \%)$, and Malays (49.3\%), followed by Chinese (34.0\%), Indians (9.7\%), and other ethnic groups $(6.9 \%)$. We diagnosed STEMI in $46.5 \%$ of the subjects $(\mathrm{n}=67)$ and NSTE-ACS in $53.5 \%$ of the subjects $(\mathrm{n}$ $=77$ ). In patients with STEMI, $62.7 \%$ received fibrinolytic therapy $(\mathrm{n}=42)$. Table 1 shows the demographic and clinical characteristics of the subjects. The median time from symptom onset of ACS to patient arrival at ED was 3.0 hours (ranging from 1 to 96). Median comparison between STEMI and NSTE-ACS with regard to time from symptom onset to ED arrival showed a significant difference $(8 \mathrm{H}$, IQR 13.6 vs 16.0, IQR 26.3 hours, $\mathrm{p}=0.037$ ). Hypertension and diabetes were reported in more than half of the subjects, $50.7 \%$ and $69.4 \%$, respectively. While the majority of the subjects presented in a stable condition, $12.5 \%$ of the patients presented in Killip class IV $(\mathrm{n}=18)$. The study reported that $18.8 \%(\mathrm{n}=27)$ of the subjects developed VA within 72 hours from ED admission, and 14.6\% (n $=21)$ experienced MVAs. The median time of VA onset was 2.0 hours (IQR: 4.0$) .81 .5 \%(\mathrm{n}=22)$ of the patients had experienced VA within 24 hours from ED admission. The study reported a total of $16(11.1 \%)$ in-hospital deaths. Figure 1 illustrates the proportion of subjects according to the characteristics of VA and in-hospital mortality.

Table 2 demonstrates the comparison of the baseline characteristics according to the occurrence of VA. Types of ACS, duration of symptoms, baseline systolic blood pressure, and Killip class were statistically significant with the occurrence of VA $(p<0.05)$. Among these variables, Killip class IV was the only variable that significantly predicted the occurrence of VA (OR: $8.67,95 \%$ CI: $2.08-$ 36.70; $<<0.05$ ) (Table 3).

Table 4 demonstrates the comparison of baseline characteristics of subjects according to in-hospital mortality. Compared with the patients who had survived, the patients who had died had significantly lower baseline blood pressure, higher baseline blood sugar level, and higher baseline leucocyte count $(\mathrm{p}<0.05)$. Meanwhile, a predominant inhospital mortality was present among patients with Killip class IV, $66.7 \%(\mathrm{n}=10)$, and the patients had experienced
MVAs, $68.8 \%(\mathrm{n}=11)(\mathrm{p}<0.05)$. The study reported $68.8 \%(\mathrm{n}=11)$ of in-hospital mortality occurring among STEMI patients although it was not statistically significant. From the multivariate regression analysis, the occurrence of MVAs (OR: 86.37; 95\% CI: 4.16-1792.70; $<<0.05$ ) and blood sugar level (OR: 1.30; 95\% CI: 1.01-1.67; $p<0.05$ ) independently predicted in-hospital mortality among ACS patients presenting to the ED (Table 5).

\section{Discussion}

\subsection{Ventricular arrhythmia}

In this single-institution observational study, the incidence of VA was $18.8 \%$, where $14.6 \%$ were MVAs. To the best of our knowledge, this study is the first in Malaysia to report on the incidence of VA among ACS patients presenting to the ED. Patients with MVAs had an 86-fold increased risk of in-hospital mortality. Notably, most of the VAs occurred during the first 24 hours of ED admission. Thus, to improve the prognosis of these patients, early corrective measures need to be instituted, and continuous ECG telemetry is crucial in detecting the life-threatening arrhythmias.

The incidence of VA in our study was three times higher than the incidence reported by Avezum et al. based on a huge study from the GRACE registry over 6 years, which recorded a proportion of only $6.9 \%$ of VA during hospital stay [16]. This could be due to the fact that the majority of patients with STEMI $(62.7 \%)$ in our study received thrombolytic therapy as the reperfusion modality, because PCI was only available during office hours.

Before the era of PPCI, VA particularly VT was observed in around $20 \%$ of patients with myocardial infarction (MI) [3]. The occurrence of VA is expected to be high in the setting where thrombolytic therapy is still widely used as the main reperfusion strategy as is the case in our setting.

Among the STEMI patients who developed VA, $12(66.7 \%)$ had received thrombolysis in ED before developing the arrhythmia. However, only six (22.2\%) of the 27 VA patients had undergone PCI before developing the arrhythmia. MI patients, who underwent PPCI as the main reperfusion strategy, had shown less occurrence of VA than thrombolytics $[4,10,11]$. Similarly, thrombolysis did not show a reduction in the occurrence of VA as shown 
TA B L E 4. Baseline characteristics according to in-hospital mortality.

\begin{tabular}{|c|c|c|c|}
\hline \multirow[b]{2}{*}{ Variables } & \multicolumn{2}{|c|}{ In-hospital mortality } & \multirow[b]{2}{*}{ p value } \\
\hline & Yes & No & \\
\hline & $n=16$ & $\mathrm{n}=\mathbf{1 2 8}$ & \\
\hline Mean age $\pm \mathrm{SD}$, years & $58.7 \pm 13.7$ & $58.7 \pm 12.7$ & 1 \\
\hline \multicolumn{4}{|l|}{ Gender, n (\%): } \\
\hline Male & $13(81.3)$ & $111(86.7)$ & \\
\hline Female & $3(18.8)$ & $17(13.3)$ & 0.468 \\
\hline \multicolumn{4}{|l|}{ Race, n (\%): } \\
\hline Malay & $9(56.3)$ & $62(48.4)$ & \\
\hline Chinese & $5(31.3)$ & $44(34.4)$ & \\
\hline Indian & $2(12.5)$ & $12(9.4)$ & \\
\hline Others & 0 & $10(7.8)$ & 0.657 \\
\hline \multicolumn{4}{|l|}{ Diagnosis, $\mathrm{n}(\%)$ : } \\
\hline STEMI & $11(68.8)$ & $56(43.8)$ & \\
\hline NSTE-ACS & $5(31.3)$ & $72(56.3)$ & 0.068 \\
\hline Median time from symptom onset to ED arrival (IQR) (hours) & $3.0(9.0)$ & $4.0(8.0)$ & 0.167 \\
\hline \multicolumn{4}{|l|}{ Mean blood pressure $\pm \mathrm{SD}, \mathrm{mmHg}$} \\
\hline Systolic blood pressure & $102.1 \pm 31.3$ & $137.4 \pm 29.4$ & 0.002 \\
\hline Diastolic blood pressure & $60.8 \pm 20.3$ & $79.3 \pm 17.0$ & 0.001 \\
\hline On arrival heart rate, mean $\pm \mathrm{SD}$, beats $/$ min & $84.6 \pm 28.1$ & $82.8 \pm 23.0$ & 0.328 \\
\hline Baseline blood sugar mean $\pm \mathrm{SD}, \mathrm{mmol} / \mathrm{L}$ & $16.4 \pm 9.0$ & $11.1 \pm 5.9$ & 0.001 \\
\hline \multicolumn{4}{|l|}{ Baseline blood laboratory data: } \\
\hline Leucocytes, mean $\pm \mathrm{SD},\left(\times 10^{9} / \mathrm{L}\right)$ & $14.7 \pm 7.4$ & $11.3 \pm 3.9$ & 0.005 \\
\hline Potassium, mean $\pm \mathrm{SD}, \mathrm{mmol} / \mathrm{L}$ & $4.1 \pm 0.5$ & $4.0 \pm 0.4$ & 0.55 \\
\hline Hemoglobin, mean $\pm \mathrm{SD}, \mathrm{g} / \mathrm{dL}$ & $13.1 \pm 2.2$ & $13.6 \pm 1.7$ & 0.144 \\
\hline \multicolumn{4}{|l|}{ Comorbidities, n (\%): } \\
\hline HTN & $12(75.0)$ & $88(69.3)$ & 0.777 \\
\hline COPD & $2(12.5)$ & $3(2.4)$ & 0.101 \\
\hline $\mathrm{DM}$ & $6(37.5)$ & $67(53.6)$ & 0.291 \\
\hline Kidney disease & $4(25.0)$ & $22(17.6)$ & 0.496 \\
\hline Hypercholesterolemia & $7(43.8)$ & 49 (38.9) & 0.788 \\
\hline Smoking history & $9(56.3)$ & $44(35.8)$ & 0.17 \\
\hline History of PCI & $2(12.5)$ & $16(13.0)$ & 1 \\
\hline History of CABG & $1(6.3)$ & $12(9.7)$ & 1 \\
\hline \multicolumn{4}{|l|}{ Electrocardiographic features: } \\
\hline ST-segment depression, n (\%) & $13(81.3)$ & $7961.7)$ & 0.262 \\
\hline ST-segment elevation, n (\%) & $11(68.8)$ & $65(50.8)$ & 0.289 \\
\hline T-wave inversion, $\mathrm{n}(\%)$ & $4(25.0)$ & $48(37.5)$ & 0.411 \\
\hline Mean heart rate \pm SD $(\mathrm{msec})$ & $90 \pm 29$ & $82 \pm 24$ & 0.188 \\
\hline Mean PR interval \pm SD (msec) & $167 \pm 68$ & $173 \pm 32$ & 0.589 \\
\hline Mean QT interval \pm SD $(\mathrm{msec})$ & $428 \pm 54$ & $423 \pm 38$ & 0.638 \\
\hline \multicolumn{4}{|l|}{ Killip classification, $\mathrm{n}(\%)$ : } \\
\hline I & $2(13.3)$ & $58(67.4)$ & \\
\hline II & $2(13.3)$ & $14(16.3)$ & \\
\hline III & $1(6.7)$ & $6(7.0)$ & \\
\hline IV & $10(66.7)$ & $8(9.3)$ & $<0.001$ \\
\hline Incidence of MVAs, n (\%) & $11(68.8)$ & $10(7.8)$ & $<0.001$ \\
\hline
\end{tabular}

in a huge landmark Global Utilization of Streptokinase t-PA for Occluded Coronary Arteries (GUSTO-I) trial [7]. Therefore, it is not surprising that the occurrence of VA is still relatively high in our study.

Killip classification has been associated with VA occurrence in ACS patients [1, 16, 17]. Henkel et al. reported the 
TA B L E 5. Multivariate regression analysis of predictors to in-hospital mortality.

\begin{tabular}{|lccc|}
\hline Variables & OR & $\mathbf{9 5 \%}$ CI & p value \\
\hline Diagnosis of ACS (STEMI vs. NSTE-ACS) & 0.62 & $0.06-6.05$ & 0.683 \\
\hline MVAs vs. non-MVAs & 86.37 & $4.16-1792.70$ & $\mathbf{0 . 0 0 4}$ \\
\hline Baseline systolic blood pressure, $\mathrm{mmHg}$ & 0.95 & $0.89-1.02$ & 0.167 \\
\hline Baseline diastolic blood pressure, mmHg & 0.98 & $0.88-1.09$ & 0.716 \\
\hline Baseline blood sugar, mmol/L & 1.3 & $1.01-1.67$ & $\mathbf{0 . 0 4}$ \\
\hline Leucocyte level, X 10 ${ }^{9} / \mathrm{L}$ & 1.04 & $0.85-1.28$ & 0.721 \\
\hline Killip class (reference: class I) & & & \\
Killip class II & 6.54 & $0.21-203.33$ & 0.284 \\
\hline Killip class III & 0.29 & $0.01-11.86$ & 0.518 \\
\hline Killip class IV & 13.96 & $0.72-269.45$ & 0.081 \\
\hline
\end{tabular}

association of VA with Killip III and IV classifications [1], which was supported by Newby et al. [7] and in agreement with our findings that indicated that the larger the area of MI, the higher the risk of MVAs [18]. Killip classification, which was introduced in 1967, risk-stratified patients with MI [19] and had also shown a significant association with mortality [20-22]. However, it did not show a statistical significance for the prediction of in-hospital mortality in our study.

Several factors had been previously investigated, which significantly predict the occurrence of VA, such as STEMI diagnosis [23], age [16], biochemical parameters such as leukocytosis [9, 24], glucose level [24], acidosis [25], potassium level $[9,26]$, and electrocardiographic features [27]. However, none of these factors predict the occurrence of VA in our study.

\subsection{In-hospital mortality}

The in-hospital mortality rate was extremely high in patients with MVA in our study. One potential explanation for the high in-hospital mortality rates reported in this observational study is the severity level. The patients that died were most likely be of the higher Killip class and had higher leucocyte level with poor glycemic control (Table 4). As VA predicts in-hospital and long-term deaths [16], it is crucial to identify ACS patients at risk of developing VA to improve the short- and long-term outcome.

Arguably, STEMI diagnosis has been implicated with a more severe clinical outcome than NSTE-ACS [28]. In previous studies, VA occurrence was significantly higher in the STEMI than the NSTE-ACS group as reflected from the pathophysiology of STEMI in which coronary vessels that are fully occluded cause an infarction involving all the layers of the heart which are suitable substrates for reentry circuit formation, rendering the heart prone to arrhythmia [27]. Nevertheless, in our study, STEMI diagnosis did not show a significant association as well as predictive value for VA and in-hospital mortality. The mean time of arrival to ED was significantly earlier among STEMI patients compared with NSTE-ACS patients, possibly resulting in timely definitive therapy. Furthermore, none of the thrombolyzed patients showed failed thrombolysis, indicating possible successful reperfusion therapy, hence limiting the damage and scar formation.

Occurrence of MVA is a strong predictive factor for inhospital and long-term mortality in ACS patients $[16,23]$. The identified causative factors that include scar formation, reentry pathway, and hyperinnervation of myocardium following MI have been attributed to the pathogenesis of VA [29, 30]. Following MI, necrosis of cardiomyocytes ensues, which subsequently undergoes a reparative process to maintain the structural integrity of the myocardium. The myocardium undergoes a complex phase of remodeling and ventricular healing, where alterations of the structure, morphology, and biochemical processes occur [31]. The most prominent in the remodeling phase is the formation of scar with fibrosis, which is vulnerable to the generation of VA [31].

In different development, Kostin et al. discovered, from a molecular study, that alterations in cell-to-cell coupling following the redistribution of connexins may contribute to the occurrence of reentrant tachycardias in the infracted zone [32]. The nerve-sprouting hypothesis is one of the most interesting theories regarding the pathogenesis of VA, particularly for VF. Increased sympathetic innervation preceded by nerve regeneration and myocardial hyperinnervation following an infarct was suggested to play crucial roles in the development of cardiac arrhythmia. Immediately after an infarct, the myocardium sustains nerve damage and regional denervation [33]. This is subsequently followed by neurilemma cell proliferation and axonal regeneration (nerve sprouting) [34], which consequently results in a global increase in adrenergic nerve density (sympathetic hyperinnervation), hence amplifying the risk and propensity for VA [35].

Systolic failure secondary to acute MI correlates well with left ventricular ejection fraction, which is a known prognostic parameter for short- and long-term risk of mortality and sudden cardiac death [36]. The patients who died had a significantly lower mean systolic and diastolic blood pressure on presentation to the ED. Although both parame- 


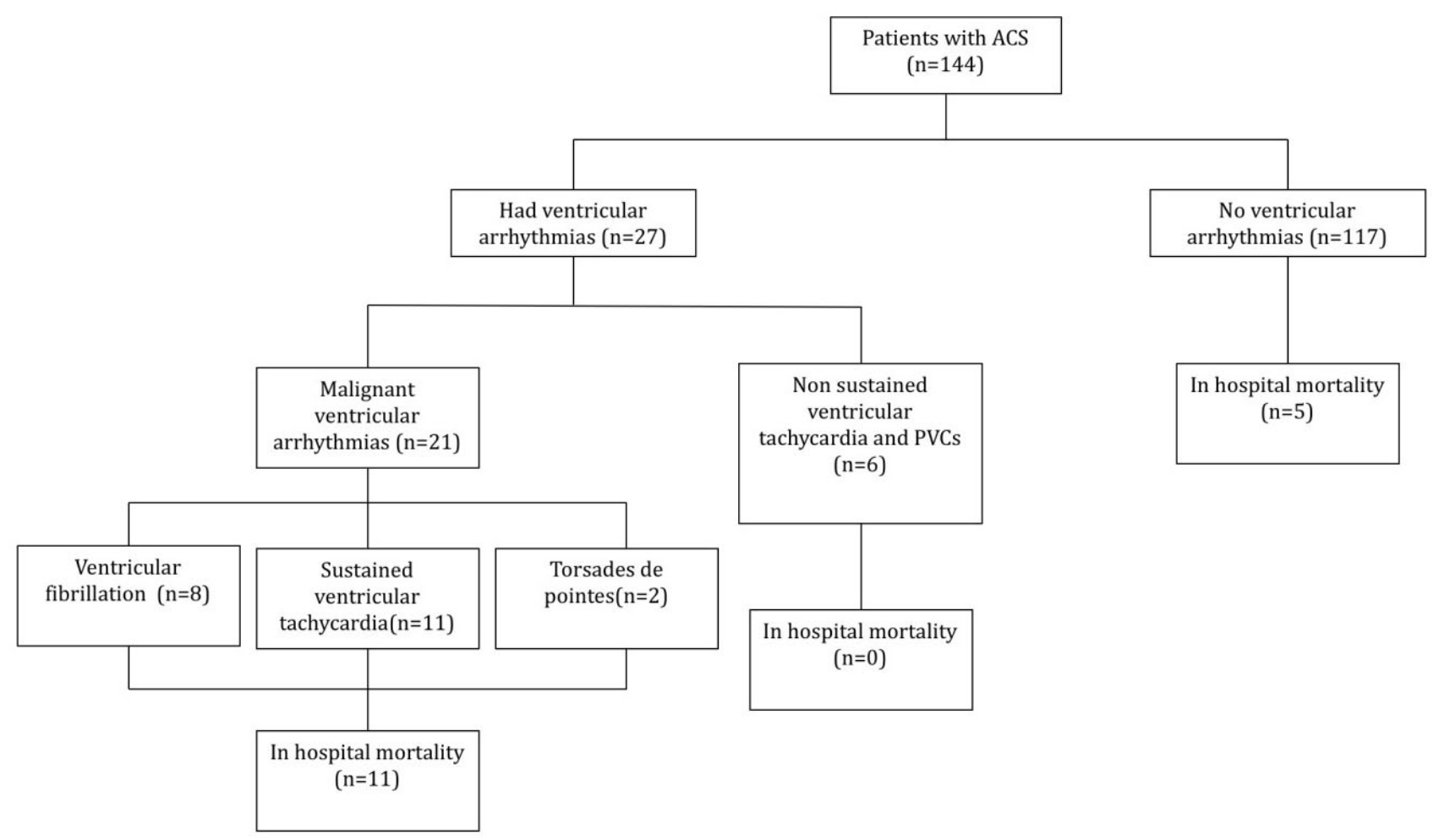

F I G U RE 1. The characteristics of VA and in-hospital mortality.

ters did not show a statistical significance predictive value regarding the development of VA and in-hospital mortality, they may correlate with the severity of MI, considering that lower blood pressure is a marker of cardiogenic shock. From the clinical practice standpoint, this finding supports the need for clinicians to be more vigilant regarding blood pressure changes among ACS patients during the early course of ED stay.

The mean glucose level at presentation was significantly higher among ACS patients who died in our study. This finding was supported by Sanjuan et al. that highlighted the impact of stress hyperglycemia as an independent risk factor for VA and death among STEMI patients [37]. Glucose level above $140 \mathrm{mg} / \mathrm{dL}(7.8 \mathrm{mmol} / \mathrm{L})$ was associated with a twofold increase of in-hospital mortality risk, regardless of the diabetic status [37,38]. This finding further emphasizes the need for aggressive glycemic control among MI patients, independent of the diabetic background.

Time-based risk assessment showed that $81.5 \%$ of VA occurred within the first 24 hours from the onset of symptoms. This finding was consistent with previous studies that also demonstrated early VA occurrence among ACS patients [4, 10, 23], which signifies a higher risk of mortality [23]. The findings further reiterate the current recommendations of 24 to 48 hours of continuous electrocardiographic monitoring in patients with MI [39]. However, in-hospital settings with backlog issues, this group of patients may end up in the ED longer than 24 hours. Close monitoring and continuous telemetry should be made compulsory to avoid missing the life-threatening arrhythmia, and priority should be given for coronary rehabilitation ward, coronary care unit, or intensive care unit admission.

\section{Conclusion}

One major finding from this observational study was the 86-fold increased risk of in-hospital mortality among ACS patients who developed VA, with most arrhythmias occurring during the first 24 hours from ED admission. Recognition of risk factors for VA is crucial in aiding the treating physicians to institute early corrective measures. Our study indicates the need for a predictive scoring model to be formulated to systematically identify the high-risk patients. With such events being difficult to treat and detect, our study also reiterates the recommendations of continuous ECG monitoring for 24 to 48 hours in high-risk groups. It is recommended that a larger prospective study be conducted to further determine the possible variables associated with the occurrence of VA and in-hospital mortality.

\section{Limitation}

This study has a relatively small sample size and was conducted in a single center. A larger prospective multicenter study may provide a better representation of our population. In addition, the study sample was inclusive of all types of ACS: UA, NSTEMI, and STEMI. In this study, UA and NSTEMI were grouped together as NSTE-ACS. As some of the NSTE-ACS patients were admitted to the general ward without continuous ECG telemetry, the true incidence of MVA in the NSTE-ACS group may have been underreported. The study had to exclude the troponin levels 
in the analysis due to a sudden change in the hospital policy for troponin use. Therefore, the association of troponin with the outcome under study cannot be ascertained.

\section{ACKNOWLEDGEMENTS}

The authors acknowledge the invaluable support received from the Faculty of Medicine of Universiti Kebangsaan Malaysia.

\section{CONFLICT OF INTEREST}

The authors declare that there is no conflict of interest regarding the publication of this article.

\section{REFERENCES}

[1] Henkel DM, Witt BJ, Gersh BJ, Jacobsen SJ, Weston SA, Meverden RA, et al. Ventricular arrhythmias after acute myocardial infarction: a 20-year community study. Am Heart J. 2006;151:806-12.

[2] Bigger JT. Definition of benign versus malignant ventricular arrhythmias: targets for treatment. Am J Cardiol. 1983;52:C47-C54.

[3] Tavli T, Avsar A, Korkut B, Dogan A. Arrhythmia due to reperfusion after thrombolytic therapy in patients with acute myocardial infarction. East J Med. 2004;9:17.

[4] Cricri P, Trachsel LD, Müller P, Wäckerlin A, Reinhart WH, Bonetti PO. Incidence and time frame of life-threatening arrhythmias in patients with ST-segment elevation myocardial infarction undergoing primary percutaneous coronary intervention. Swiss Med Wkly. 2012;142:3604.

[5] Cao J-M, Chen LS, KenKnight BH, Ohara T, Lee M-H, Tsai J, et al. Nerve sprouting and sudden cardiac death. Circ Res. 2000;86:816-21.

[6] Antman EM, Hand M, Armstrong PW, Bates ER, Green LA, Halasyamani LK, et al. 2007 Focused update of the ACC/AHA 2004 guidelines for the management of patients with ST-elevation myocardial infarction. Circulation. 2008;117:296-329.

[7] Newby KH, Thompson T, Stebbins A, Topol EJ, Califf RM, Natale A. Sustained ventricular arrhythmias in patients receiving thrombolytic therapy: incidence and outcomes. Circulation. 1998;98:2567-73.

[8] O'Gara PT, Kushner FG, Ascheim DD, Casey DE, Chung MK, De Lemos JA, et al. 2013 ACCF/AHA guideline for the management of ST-elevation myocardial infarction: a report of the American College of Cardiology Foundation/American Heart Association Task Force on Practice Guidelines. J Am Coll Cardiol. 2013;61:e78-e140.

[9] Rahimi K, Watzlawek S, Thiele H, Secknus M-A, Hayerizadeh BF, Niebauer J, et al. Incidence, time course, and predictors of early malignant ventricular arrhythmias after non-ST-segment elevation myocardial infarction in patients with early invasive treatment. Eur Heart J. 2006;27:1706-11.

[10] Ohlow M-A, Geller JC, Richter S, Farah A, Müller S, Fuhrmann JT, et al. Incidence and predictors of ventricular arrhythmias after ST-segment elevation myocardial infarction. Am J Emerg Med. 2012;30:580-6.

[11] Antman EM, Anbe DT, Armstrong PW, Bates ER, Green LA, Hand $\mathrm{M}$, et al. ACC/AHA guidelines for the management of patients with ST-elevation myocardial infarction: a report of the American College of Cardiology/American Heart Association Task Force on Practice Guidelines (Committee to Revise the 1999 Guidelines for the Management of Patients with Acute Myocardial Infarction). J Am Coll Cardiol. 2004;44:E1-E211.

[12] Steg PG, James SK, Atar D, Badano LP, Lundqvist CB, Borger MA, et al. ESC Guidelines for the management of acute myocardial infarction in patients presenting with ST-segment elevation: The Task Force on the management of ST-segment elevation acute myocardial infarction of the European Society of Cardiology (ESC). Eur Heart J. 2012;33:2569-619.

[13] Amsterdam EA, Wenger NK, Brindis RG, Casey DE, Ganiats TG, Holmes DR, et al. 2014 AHA/ACC guideline for the management of patients with non-ST-elevation acute coronary syndromes: a report of the American College of Cardiology/American Heart Association Task Force on Practice Guidelines. J Am Coll Cardiol. 2014;64:e139e228.

[14] Thygesen K, Alpert JS, White HD. Joint ESC/ACCF/AHA/WHF Task Force for the Redefinition of Myocardial Infarction. G Ital Cardiol (rome). 2008;9:209-22.

[15] Zambahari R, Rajadurai J, Fong A, Chandran A, Hooi CG, Salleh NA, et al. Malaysia CPG for STEMI. ASEAN Heart J. 2014;1:1-6.

[16] Avezum Á, Piegas LS, Goldberg RJ, Brieger D, Stiles MK, Paolini $\mathrm{R}$, et al. Magnitude and prognosis associated with ventricular arrhythmias in patients hospitalized with acute coronary syndromes (from the GRACE Registry). Am J Cardiol. 2008;102:1577-82.

[17] Cripps T, Bennett D, Camm J, Ward D. Prospective evaluation of clinical assessment, exercise testing and signal-averaged electrocardiogram in predicting outcome after acute myocardial infarction. Am J Cardiol. 1988;62:995-9.

[18] Gatzoulis KA, Archontakis S, Dilaveris P, Tsiachris D, Arsenos P, Sideris $\mathrm{S}$, et al. Ventricular arrhythmias: from the electrophysiology laboratory to clinical practice. Part I: malignant ventricular arrhythmias. Hellenic J Cardiol. 2011;52:525-35.

[19] Killip III T, Kimball JT. Treatment of myocardial infarction in a coronary care unit: a two year experience with 250 patients. Am J Cardiol. 1967;20:457-64

${ }^{[20]}$ Kerry L. Lee, Lynn H. Woodlief, Eric J. Topol, W. Douglas Weaver, Amadeo Betriu, Jacques Col, et al. Predictors of 30-Day Mortality in the Era of Reperfusion for Acute Myocardial Infarction Results From an International Trial of 41021 Patients. Circulation. 1995;91:165968.

[21] Rott D, Behar S, Gottlieb S, Boyko V, Hod H. Usefulness of the Killip Classification for Early Risk Stratification of Patients With Acute Myocardial Infarction in the 1990s Compared With Those Treated in the 1980s 1. Am J Cardiol. 1997;80:859-64.

[22] Willems AR, Tijssen JG, van Capelle FJ, Kingma JH, Hauer RN, Vermeulen FE, et al. Determinants of prognosis in symptomatic ventricular tachycardia or ventricular fibrillation late after myocardial infarction. J Am Coll Cardiol. 1990;16:521-30.

[23] Orvin K, Eisen A, Goldenberg I, Gottlieb S, Kornowski R, Matetzky $\mathrm{S}$, et al. Outcome of contemporary acute coronary syndrome complicated by ventricular tachyarrhythmias. EP Europace. 2015;18:21926.

[24] Chen J-H, Tseng C-L, Tsai S-H, Chiu W-T. Initial serum glucose level and white blood cell predict ventricular arrhythmia after first acute myocardial infarction. Am J Emerg Med. 2010;28:418-23.

[25] Nagai T, Anzai T, Kaneko H, Anzai A, Mano Y, Nagatomo Y, et al. Impact of systemic acidosis on the development of malignant ventricular arrhythmias after reperfusion therapy for ST-elevation myocardial infarction. Circ J. 2010;74:1808-14.

[26] Su J, Fu X, Tian Y, Ma Y, Chen H, Wang Y, et al. Additional predictive value of serum potassium to Thrombolysis In Myocardial Infarction risk score for early malignant ventricular arrhythmias in patients with acute myocardial infarction. Am J Emerg Med. 2012;30:1089-94.

[27] Arsenos P, Gatzoulis K, Dilaveris P, Manis G, Tsiachris D, Archontakis S, et al. Arrhythmic sudden cardiac death: substrate, mechanisms and current risk stratification strategies for the postmyocardial infarction patient. Hellenic J Cardiol. 2013;54:301-15.

[28] Chan MY, Sun JL, Newby LK, Shaw LK, Lin M, Peterson $\mathrm{ED}$, et al. Long-term mortality of patients undergoing cardiac catheterization for ST-elevation and non-ST-elevation myocardial infarction. Circulation. 2009;119:3110.

[29] Cao J-M, Fishbein MC, Han JB, et al. Relationship between regional cardiac hyperinnervation and ventricular arrhythmia. Circulation. 2000;101:1960-9.

[30] Cao J-M, Chen LS, KenKnight BH, et al. Nerve sprouting and sudden cardiac death. Circ Res. 2000;86:816-21. 
[31] Bakker JMd, Rijen HVv. Mechanisms of ventricular tachycardia : underlying pathological and physiological abnormalities. In: Wang PJ, A. Al-Ahmad, H.Hsia, P.C.Zei, editors. Ventricular Arrhythmia and Sudden Cardiac Death. 1st ed. Massachusetts: Blackwell Publishing; 2008.

[32] Kostin S, Rieger M, Dammer S, Hein S, Richter M, Klövekorn W$\mathrm{P}$, et al. Gap junction remodeling and altered connexin43 expression in the failing human heart. Cardiac Cell Biology: Springer; 2003. p. 135-44.

[33] Inoue H, DP Z. Time course of denervation of efferent sympathetic and vagal nerves after occlusion of the coronary artery in the canine heart. Circ Res. 1988;62:1111-20.

[34] Vracko R, D T, RG F. Nerve fibers in human myocardial scars. Hum Pathol. 1991;22:138-46.

[35] Chen LS, Chen P-S, S.Swissa M. The mechanisms of ventricular fibrillation. In: P.J Wang, A.Al-Ahmad, H.Hsia, Zei PC, editors. Ventricular Arrhythmias and Sudden Cardiac Death. 1st ed. Massachusetts: Blackwell Publishing; 2008.

[36] Markman TM, Nazarian S. Treatment of ventricular arrhythmias: What's New? Trends Cardiovasc Med. 2019;29:249-61.

[37] Sanjuán R, Núñez J, Blasco ML, Miñana G, Martínez-Maicas H,
Carbonell N, et al. Prognostic implications of stress hyperglycemia in acute ST elevation myocardial infarction. Prospective observational study. Revista Española de Cardiología (English Edition). 2011;64:201-7.

[38] Wahab NN, Cowden EA, Pearce NJ, Gardner MJ, Merry H, Cox JL, et al. Is blood glucose an independent predictor of mortality in acute myocardial infarction in the thrombolytic era? J Am Coll Cardiol. 2002;40:1748-54.

[39] Hasin Y, Danchin N, Filippatos GS, Heras M, Janssens U, Leor J, et al. Recommendations for the structure, organization, and operation of intensive cardiac care units. Eur Heart J. 2005;26:1676-82.

How to cite this article: Azlan Helmy Abd Samat, Hashim Embong, Husyairi Harunarashid, Oteh Maskon. Predicting Ventricular Arrhythmias and In-Hospital Mortality in Acute

Coronary Syndrome Patients Presenting to the Emergency Department. Signa Vitae. 2020;16(1):55-64. doi: $10.22514 /$ sv.2020.16.0008. 